\title{
Construction of Bacillus anthracis mutant strains producing a single toxin component
}

\author{
Corinne Pezard, Edith Duflot and Michìle MocK* \\ Laboratoire de Génétique Moléculaire des Toxines (URA 557, CNRS), Institut Pasteur, 28 rue du Docteur Roux, \\ 75724 Paris Cedex 15, France
}

(Received 24 February 1993; revised 1 May 1993; accepted 10 May 1993)

\begin{abstract}
The two protein exotoxins secreted by Bacillus anthracis are composed of three distinct components: protective antigen (PA), lethal factor (LF), and (o)edema factor (EF). We have developed a genetic strategy that permits us selectively to inactivate each of the genes coding for PA, EF or LF. This strategy involved the deletion of a portion of the structural gene and the insertion of an antibiotic resistance cassette. With this technique, double mutant strains of $B$. anthracis producing only one toxin component have been constructed. Characterization of the mutant strains indicated that they produced the expected single toxin protein. Using a simple, two-step protocol, we have purified PA, LF and EF to homogeneity from culture supernatants. These three mutant strains are potentially powerful tools for studying the individual effect of each toxin component in vitro and in vivo.
\end{abstract}

\section{Introduction}

Bacillus anthracis, the aetiological agent of anthrax, secretes three separate proteins - protective antigen (PA; $85 \mathrm{kDa})$, (o)edema factor ( $\mathrm{EF} ; 89 \mathrm{kDa}$ ) and lethal factor $(\mathrm{LF} ; 83 \mathrm{kDa})$ - that make up the two anthrax toxins (Stanley \& Smith, 1961; Fish et al., 1968b; Leppla, 1984). Individually, none of the three toxin components has any biological effect (Smith \& Stoner, 1967). PA combined with LF forms the lethal toxin whereas oedema toxin consists of PA and EF (Beall et al., 1962; Smith \& Stoner, 1967). PA is the common receptor-binding component mediating entry of either LF or EF into target cells (Leppla, 1984). EF has been shown to be a calmodulin-dependent adenylate cyclase (Leppla, 1982). The mode of action of LF remains unknown.

Fully virulent strains of $B$. anthracis possess two large plasmids, $\mathrm{pXO1}$ and $\mathrm{pXO}$. pXO2 codes for the formation of a poly-D-glutamic acid capsule (Avakyan $e t$ al., 1965; Uchida et al., 1985), whereas toxin production is conferred by pXO1 (Mikesell et al., 1983) which carries the toxin structural genes. These three genes, pag, cya and lef, coding for PA, EF and LF, respectively, have been cloned and sequenced (Bragg \& Robertson, 1989;

*Author for correspondence. Tel. +33145688312 ; fax +33145 688954.

Abbreviations: EF, (o)edema factor; LF, lethal factor; PA, protective antigen.
Escuyer et al., 1988; Mock et al., 1988; Welkos et al., 1988 ), thus providing the basis for genetic studies.

Most of the available data on toxin mode of action have been obtained with toxin components purified from culture supernatants of the Sterne strain (Beall et al., 1962; Fish et al., $1968 a$; Smith \& Stoner, 1967). Because of the difficulty in separating the three proteins from each other, several strategies have been developed in an attempt to increase purity. These approaches include multi-step chromatographic procedures (Leppla, 1988; Quinn et al., 1988) or expression in different bacterial systems (Vodkin \& Leppla, 1983; Ivins \& Welkos, 1986; Iacono-Connors et al., 1990).

We have previously devised a genetic strategy allowing the construction of $B$. anthracis mutant strains deficient in one toxin component (Cataldi et al., 1990; Pezard et al., 1991). We have extended this genetic approach to the construction of double mutant strains with the aim of producing PA, EF and LF as single toxin components from $B$. anthracis. Use of these mutant strains in toxin preparation precludes the possibility of cross-contamination by individual toxin components, and should prove to be a useful and convenient tool for purifying each protein to homogeneity.

\section{Methods}

Bacterial strains, plasmids and culture media. Escherichia coli $\mathrm{HB} 101$ harbouring the mobilizing plasmid pRK212.1 (Trieu-Cuot et al., 1987) was used in conjugal transfer experiments. Shuttle plasmid 
Table 1. Bacterial strains and plasmids

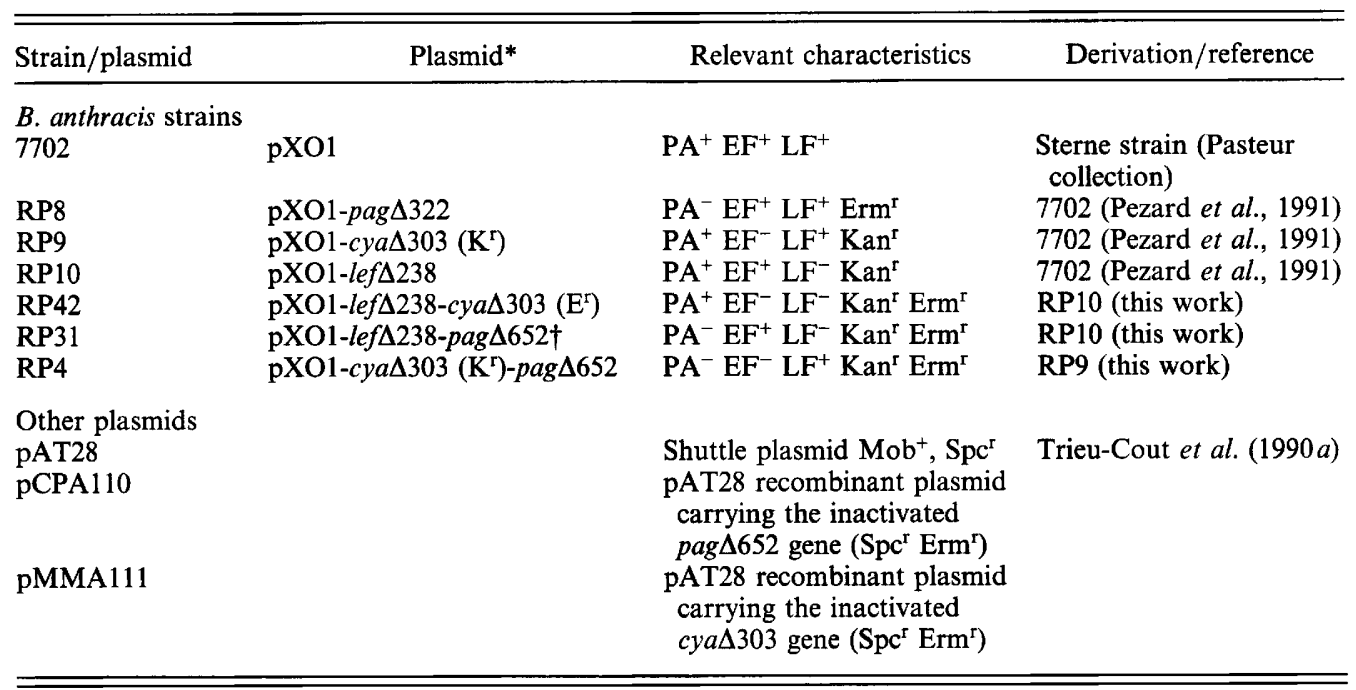

* Plasmid designations: the number after $\Delta$ indicates the gene codon at which the deletion starts; $\mathrm{E}^{\mathrm{r}}, \mathrm{K}^{\mathrm{r}}$ indicate the insertion of an erythromycin $(\mathrm{E})$ or kanamycin $(\mathrm{K})$ resistance cassette into cya $\Delta 303$ (Trieu-Cuot et al., $1990 \mathrm{~b}$ ).

$\dagger$ pag $\Delta 652$ : deletion begins at nucleotide 1272 and ends at nucleotide 3759 (codon 652) using the numbering from the published sequence of pag (Welkos et al., 1988).

pAT28 (Trieu-Cuot et al., 1990a), conferring spectinomycin resistance $\left(\mathrm{Spc}^{\mathrm{r}}\right)$ was used as the vector for transferring DNA into Bacillus anthracis strains. The mating procedure used for conjugal transfer of recombinant plasmids from $E$. coli to $B$. anthracis was as previously described (Pezard et al., 1991).

E. coli was grown in L broth or L agar (Miller, 1972), and $B$. anthracis was grown in brain-heart infusion (BHI) medium (Difco). Rmedium (Ristroph \& Ivins, 1983) was used for toxin production. Antibiotics were used at the following concentrations: ampicillin, $100 \mu \mathrm{g} \mathrm{ml}^{-1}$ for $E$. coli cultures; spectinomycin, 100 and $60 \mu \mathrm{g} \mathrm{ml}^{-1}$ for $E$. coli and $B$. anthracis cultures, respectively; erythromycin, 180 and $10 \mu \mathrm{g} \mathrm{ml}^{-1}$ for $E$. coli and $B$. anthracis cultures, respectively.

Spores of $B$. anthracis strains were prepared as previously described (Pezard et al., 1991).

DNA techniques. pXO1 was prepared by the method of Green $e t$ al. (1985). Methods for recombinant DNA manipulations were as described by Sambrook et al. (1989). DNA fragments were prepared from agarose gels using the Geneclean Kit (Bio 101). Recombinant plasmid pACP41, a pUC8 derivative which contains the $3.4 \mathrm{~kb}$ XhoI-BamHI fragment carrying pag was used for construction of pCPA110. A $2.5 \mathrm{~kb}$ Hincll deletion starting at position 1272 and stopping at 3759 (from the previously published pag nucleotide sequence, Welkos et al., 1988) was created in pACP41 and the Erm ${ }^{\mathrm{r}}$ cassette was inserted into the HincII site. The resulting DNA fragment carrying pag $\Delta 652$ was then subcloned in the shuttle plasmid pAT28 yielding pCPA110.

Southern blot DNA hybridizations were performed with Hybond$\mathrm{N}^{+}$nylon membranes (Amersham). DNA probes were labelled using the ECL labelling system (kit RPN3000, Amersham).

Protein analysis and adenylate cyclase assay. SDS-PAGE $(8 \%, \mathrm{w} / \mathrm{v}$, acrylamide) was performed as described by Laemmli (1970). Gels were stained with Coomassie blue or subjected to immunoblot analysis (Towbin et al., 1979). Western blots (immunoblots) were probed with rabbit sera raised against LF or PA purified from polyacrylamide gels or against a truncated form of EF (CYA 62) (Labruyère et al., 1990).

Adenylate cyclase was assayed in $B$. anthracis $\mathrm{R}$-medium culture supernatants as previously described (Ladant, 1988). Enzymic activity is expressed in units $\mathrm{ml}^{-1}$. One unit corresponds to $1 \mathrm{nM}$-cAMP formed in $1 \mathrm{~min}$ at $30^{\circ} \mathrm{C}$.

Purification of toxin components. Toxin components were prepared from $B$. anthracis mutant strains as follows. Colonies freshly grown on $\mathrm{BHI} / 5 \%(\mathrm{v} / \mathrm{v})$ blood agar were used to inoculate $500 \mathrm{ml} \mathrm{R}$-medium (Ristroph \& Ivins, 1983) in a 1 litre flask. Cultures were grown at $37^{\circ} \mathrm{C}$ for $15 \mathrm{~h}$ without shaking in an atmosphere of $5 \%(\mathrm{v} / \mathrm{v}) \mathrm{CO}_{2}$. Culture supernatants ( 41 ) were filtered through a $0.45 \mu \mathrm{m}$ pore-size membrane (Nalgene). The cell-free filtrate was concentrated 40 -fold by ultrafiltration through PTGC membranes (molecular mass cut-off, $10000 \mathrm{Da}$ ) in a Minitan system (Millipore). Protein was precipitated overnight at $4{ }^{\circ} \mathrm{C}$ by the addition of $\left(\mathrm{NH}_{4}\right)_{2} \mathrm{SO}_{4}$ to $70 \%$ saturation. The precipitate was collected by centrifugation at $35000 \mathrm{~g}$ for $30 \mathrm{~min}$ and resuspended in $2 \mathrm{ml} 10 \mathrm{~mm}$-Tris/ $\mathrm{HCl} \mathrm{pH} \mathrm{8.0.} \mathrm{Crude} \mathrm{toxin} \mathrm{preparations}$ were desalted by dialysis, and further purified by anion-exchange chromatography over a Mono Q HR 5/5 column (FPLC, Pharmacia LKB), with $10 \mathrm{~mm}$-Tris/ $\mathrm{HCl}$ buffer $\mathrm{pH} 8.0$ and a linear $\mathrm{NaCl}$ gradient as described by Quinn et al. (1988).

Infection of mice. Female, six-week-old, pathogen-free Swiss mice were supplied by Charles River (Saint-Aubin-les Elbeuf, France) and used for determination of the lethal dose $\left(\mathrm{LD}_{50}\right)$ of each strain, as described previously (Pezard et al., 1991).

\section{Results and Discussion}

\section{Construction and characterization of double mutant B. anthracis strains}

We have described previously a genetic strategy for the construction of $B$. anthracis mutant strains deficient in the production of PA (RP8), EF (RP9), or LF (RP10). The toxin genes pag, cya and lef were inactivated by intragenic deletion and insertion of an antibiotic resistance cassette $\left(\mathrm{Erm}^{\mathrm{r}}\right.$ or $\left.\mathrm{Kan}^{\mathrm{r}}\right)$, allowing selection of recombinant strains carrying mutated genes on pXO1 
(Cataldi et al., 1990; Pezard et al., 1991). We have now extended this approach and constructed double mutant strains capable of producing only a single toxin component.

For this work, two recombinant plasmids derived from pAT28 were constructed. pCPA110 carries the pag gene inactivated through deletion and insertion of a DNA cassette conferring erythromycin resistance $\left(\mathrm{Erm}^{\mathrm{r}}\right)$. pMMA111 carries the cya gene inactivated in the same manner (cya $\Delta 303)$ as that described previously for pMMA110 (Pezard et al., 1991), except that an Erm ${ }^{\mathrm{r}}$ cassette was inserted in the gene. Mutants RP9 and RP10 were used as recipient strains for subsequent inactivation of a second toxin gene (Table 1).

pCPA110 was transferred by conjugation to RP9 or RP10. The resulting transconjugants were cultured in the absence of spectinomycin (selective antibiotic for the vector part of pCPA110) and in the presence of erythromycin (selecting for the maintenance of the cassette), to select $\mathrm{Erm}^{\mathrm{r}} \mathrm{Spc}^{\mathrm{S}}$ clones which presumably had lost pCPA110 but integrated the inactivated pag gene into pXO1 by homologous recombination. Two strains, RP4 and RP31, which originated from recipient strains RP9 and RP10, respectively, were isolated. A third $\mathrm{Erm}^{\mathrm{r}} \mathrm{Spc}^{\mathrm{S}}$ strain, RP42, was isolated from an RP10derived transconjugant carrying recombinant plasmid pMMA111. Strains RP4, RP31 and RP42 were expected to produce only LF, EF or PA, respectively, after replacement of wild-type pag (RP4, RP31) or cya (RP42). The recombinant $\mathrm{pXO1}$ from the three mutant strains was subjected to restriction analysis.

The cya gene is located on a $7.0 \mathrm{~kb} B a m \mathrm{HI}$ fragment of pXO1 (Mock et al., 1988). A BamHI digest of pXO1 originating from RP42 was cloned into pUC18 and recombinant plasmids able to confer $\mathrm{Erm}^{\mathrm{r}}$ in $E$. coli were isolated. These plasmids contained a $7.0 \mathrm{~kb} B a m H I$ fragment and restriction enzyme analysis indicated that the BamHI fragment carried inactivated cya $\Delta 303 \mathrm{E}^{\mathrm{r}}$ (Table 1).

The pag gene is located on a $6.0 \mathrm{~kb} \mathrm{BamHI}$ fragment of pXO1 (Vodkin \& Leppler, 1983). Since the $\mathrm{Erm}^{\mathrm{r}}$ cassette inserted in the gene was flanked by two BamHI sites, this enzyme could not be used for cloning inactivated pag $\Delta 652$. We expected pag $\Delta 652$ to be located on a HindIII fragment of pXO1 larger than $3.0 \mathrm{~kb}$. Therefore, we cloned HindIII digests of recombinant pXO1 originating from RP4 and RP31 into pUC18. In both cases, $\mathrm{Erm}^{\mathrm{r}} E$. coli transformants were isolated. Their respective recombinant pUC derivative plasmids carried a $4.0 \mathrm{~kb} H$ indIII fragment containing the expected pag $\Delta 652$ construction as determined by restriction enzyme analysis.

The location of the $\mathrm{Erm}^{\mathrm{r}}$ cassette on the three recombinant $\mathrm{pXO1}$ plasmids was further characterized

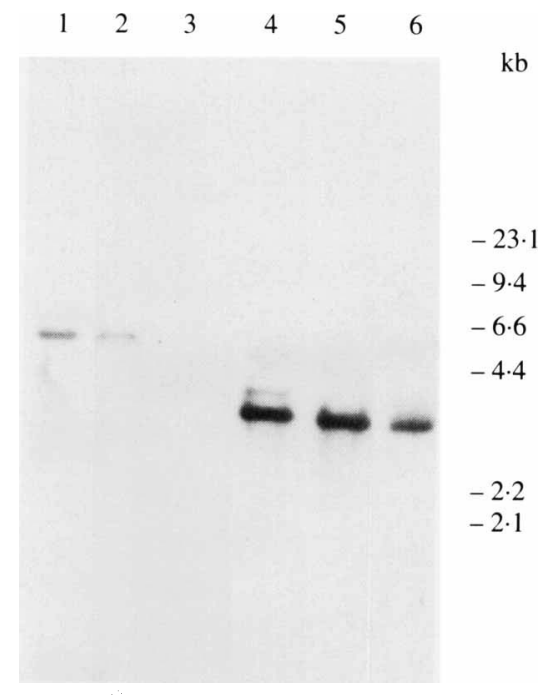

Fig. 1. Characterization of mutants by southern hybridization. A $1.2 \mathrm{~kb} \mathrm{Erm}^{\mathrm{r}}$ DNA fragment was used as probe. Plasmid DNA was digested as follows: lane 1, recombinant pUC18 plasmid containing the $7.2 \mathrm{~kb} \mathrm{BamHI}$ fragment of pXO1 carrying the inactivated cya gene digested with BamHI; lane 2, pXO1 of strain RP42 digested with BamHI; lane 3, $\lambda$ DNA digested with HindIII; lane 4, pXOl of strain RP31 digested with HindIII; lane 5, pXO1 of strain RP4 digested with HindIII; lane 6, HindIII digested recombinant pUC18 plasmid containing the $4.0 \mathrm{~kb}$ HindIII fragment of pXOl carrying the inactivated pag gene.

by Southern blot analysis. As shown in Fig. 1, a $7.0 \mathrm{~kb}$ fragment from a BamHI digest of pXO1 from RP42 (lane 2) and a $4.0 \mathrm{~kb}$ fragment from a HindIII digest of pXO1 from RP31 or RP4 (lanes 4 and 5) hybridized with the $\mathrm{Erm}^{\mathrm{r}}$ cassette when it was used as a probe. These results confirmed that for all three $B$. anthracis recombinants the $\mathrm{Erm}^{\mathrm{r}}$ cassette was located on $\mathrm{pXO1}$, within the pag coding sequence for RP4 and RP31 and within the cya coding sequence for RP42. We therefore concluded that we had constructed three mutant strains in which two of the three toxin components genes were inactivated. These strains were therefore expected to produce only one toxin component: EF from RP31, LF from RP4, and PA from RP42.

\section{Production of toxin proteins in mutant strains of B. anthracis}

The anthrax toxin components PA, EF and LF are produced by $B$. anthracis when bacteria are grown in Rmedium (Ristroph \& Ivins, 1983) and constitute the most abundant extracellular proteins (Fig. 2, lane 1). Analysis of the culture supernatants of each mutant strain, RP42, RP31 and RP4, indicated the presence of a major species of protein (Fig. 2, lanes 2, 3 and 4); these proteins were further characterized by Western blot analysis using specific antisera raised against PA, EF or LF. The supernatant proteins of strains RP42, RP31 and RP4 


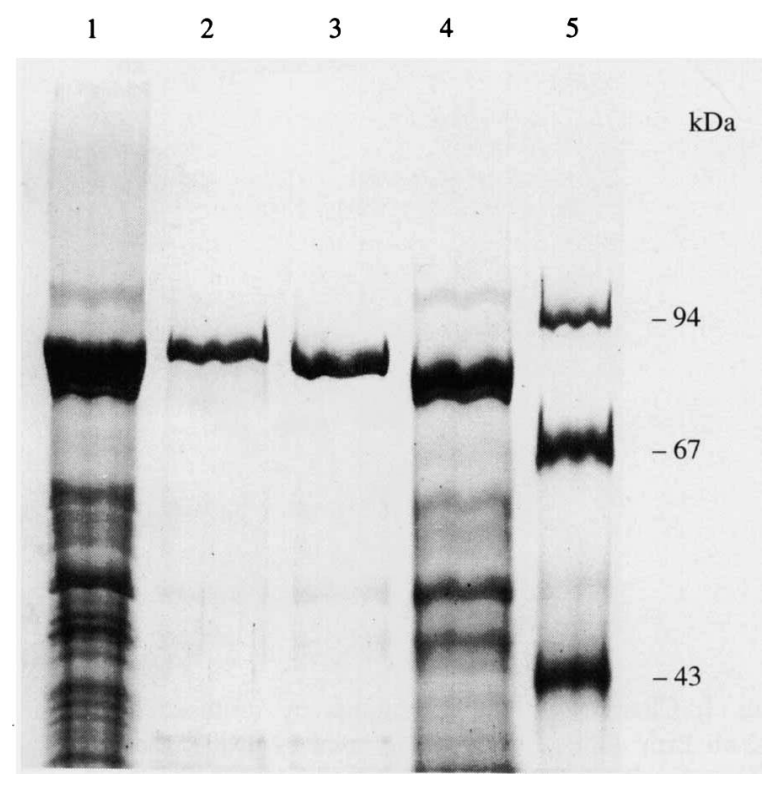

Fig. 2. SDS-PAGE analysis of culture supernatants from $B$. anthracis strains. Lane 1, parental strain 7702 (20 $\mu$ g protein); lane 2, strain RP31 (15 $\mu$ g protein); lane 3, strain RP42 (15 $\mu$ g protein); lane 4, strain RP4 (20 $\mu$ g protein); lane 5, molecular mass markers (Pharmacia).

were exclusively immunodetected with anti-PA, anti-EF, and anti-LF sera respectively (data not shown). These results confirmed that, as expected, each strain produced only one of the three toxin components.

It is known that EF is an adenylate cyclase (Leppla, 1982). To verify inactivation of the cya gene we determined adenylate cyclase activity in the culture supernatant of the three mutant strains and of parental strain 7702. No enzymic activity was detected in the supernatant of strain RP42 $\left(\mathrm{PA}^{+}\right)$, thus confirming inactivation of the cya gene. As expected, strain RP4 $\left(\mathrm{LF}^{+}\right)$derived from RP9, was also devoid of this activity. The adenylate cyclase activity found in the culture supernatant of RP31 $\left(\mathrm{EF}^{+}\right)$was similar to that of wildtype strain $7701\left(200 \mathrm{U} \mathrm{ml}^{-1}\right)$ under the same experimental conditions.

Growth of RP4, RP31 and RP42 in large culture volumes allowed us to develop a purification procedure for recovery of each toxin component. Individual toxin components are produced by the corresponding mutant strain in quantities similar to those produced by the parental strain, 7702. Each protein was thus readily available at a high degree of purity with a simple twostep purification protocol (see Methods).

\section{Virulence of $B$. anthracis mutant strains in mice}

The virulence of the three $B$. anthracis mutants was studied in mice. The strains constructed in this work are derived from RP9 and RP10, whose virulence properties have been described previously (Pezard et al., 1991).
Strain RP9 producing lethal toxin (PA + LF) causes death in mice at an $\mathrm{LD}_{50}$ of $10^{7}$. The inactivation of pag in mutant RP4 abolished the lethal effect of RP9, and inoculation of mice with $10^{9}$ spores of RP4 failed to provoke mortality. Strain RP10, producing oedema toxin $(\mathrm{PA}+\mathrm{EF})$ has no lethal effect but still induces oedema in mice after subcutaneous injection. The inactivation of pag and cya in RP31 and RP42, respectively, abolished oedema formation after subcutaneous injection of $10^{9}$ spores. Therefore, the three mutant strains we have constructed, RP4, RP42 and RP31, producing only LF, PA, or EF, respectively, are avirulent and totally devoid of biological effect. These results demonstrate that individually none of the three proteins secreted by the bacteria is toxic for animals, and they are consistent with previous observation obtained after injection of the proteins into animals (Smith \& Stoner, 1967).

The Sterne strain, which carries only pXO1, is toxigenic and uncapsulated and is currently used as the veterinary vaccine against anthrax (Hambleton et al., 1984; Sterne, 1939; Welkos \& Friedlander, 1988b). However, since this strain still produces both lethal and oedema toxins it is pathogenic to animals at high doses. Mutant strains totally devoid of lethality might contribute to an improved live vaccine. Further studies with our mutant strains should provide new insights into $B$. anthracis pathogenesis as well as into immunization against anthrax. While it is well known that PA is the main toxin component required for protection of animals and humans (Hambleton et al., 1984; Welkos \& Friedlander, 1988a), the contribution of EF and LF to the immune response remains unclear. Investigation of the protective efficacy of these strains should help to clarify the respective roles of the individual toxin components in protection against anthrax.

We are grateful to Sims Kochi and Agnès Fouet for critical reading of the manuscript. We thank Régine Lambrecht for preparation of the manuscript. Financial support came from DRET-91048.

\section{References}

Avakyan, A. A., Katz, L. N. \& Pavlova, L. B. (1965). Structure and composition of the Bacillus anthracis capsule. Journal of Bacteriology 90, 1082-1095.

Beall, F. A., Taylor, M. J. \& Thorne, C. B. (1962). Rapid lethal effects of the third component found upon fractionating the toxin of Bacillus anthracis. Journal of Bacteriology 83, 1274-1280.

BrAGG, T. S. \& RoBerTSON, D. L. (1989). Nucleotide sequence and analysis of the lethal factor gene (lef) from Bacillus anthracis. Gene 81, 45-54.

Cataldi, A., Labruyère, E. \& Mock, M. (1990). Construction and characterization of a protective antigen deficient Bacillus anthracis strain. Molecular Microbiology 4, 1111-1117.

Escuyer, V., Duflot, E., Sezer, O., Danchin, A. \& Mock, M. (1988). Structural homology between virulence-associated bacterial adenylate cyclases. Gene 71, 293-298.

Fish, D. C., Klein, F., Lincoln, R. E., Walker, J. S. \& Dobis, J. P. 
(1968a). Pathophysiological changes in the rat associated with anthrax toxin. Journal of Infectious Diseases 118, 114-124.

Fish, D. C., Mahlandt, B. G., Dobbs, J. P. \& Lincoln, R. E. (1968 b). Purification and properties of in vitro produced anthrax toxin components. Journal of Bacteriology 95, 907-918.

Green, B. D., Battisti, L., Koehler, T. M., ThORNe, L. B. \& Ivins, B. E. (1985). Demonstration of a capsule plasmid in Bacillus anthracis. Infection and Immunity 49, 291-297.

Hambleton, P., Carman, J. A. \& Melling, J. (1984). Anthrax: the disease in relation to the vaccines. Vaccine 2, 125-132.

Iacono-Connors, L. C., Schmaljohn, C. S. \& Dalrymple, J. M. (1990). Expression of the Bacillus anthracis protective antigen gene by baculovirus and vaccinia virus recombinants. Infection and Immunity 58, 366-372.

Ivins, B. E. \& Welkos, S. (1986). Cloning and expression of the Bacillus anthracis protective antigen gene in Bacillus subtilis. Infection and Immunity 54, 537-542.

Labruyère, E., Mock, M., Ladant, D., Michelson, S., Gilles, A. M., LAOÏDE, B. \& BARZU, O. (1990). Characterization of ATP and calmodulin-binding properties of a truncated form of Bacillus anthracis adenylate cyclase. Biochemistry 29, 4922-4928.

LADANT, D. (1988). Interaction of Bordetella pertussis adenylate cyclase with calmodulin: identification of two separated calmodulin-binding domains. Journal of Biological Chemistry 263, 2612-2618.

LAEMMLI, U. K. (1970). Cleavage of structural proteins during the assembly of the head of bacteriophage T4. Nature, London 227, 680-685.

LEPPLA, S. H. (1982). Anthrax toxin edema factor: a bacterial adenylate cyclase that increases cyclic AMP concentrations in eucaryotic cells. Proceedings of the National Academy of Sciences of the United States of America 79, 3162-3166.

LEPPLA, S. H. (1984). Bacillus anthracis calmodulin dependent adenylate cyclase: chemical and enzymatic properties and interactions with eucaryotic cells. Advances in Cyclic Nucleotide and Protein Phosphorylation Research 17, 189-198.

LePpla, S. H. (1988). Production and purification of anthrax toxin. Methods in Enzymology 165, 103-116.

Mikesell, P., Ivins, B. E., Ristroph, J. D. \& Dreier, T. P. (1983). Evidence for plasmid-mediated toxin production in Bacillus anthracis. Infection and Immunity 39, 371-376.

Miller, J. H. (1972). Experiments in Molecular Genetics. Cold Spring Harbor, NY: Cold Spring Harbor Laboratory.

Mock, M., Labruyère, E., Glaser, P., Danchin, A. \& Ullmann, A. (1988). Cloning and expression of the calmodulin-sensitive Bacillus anthracis adenylate cyclase in Escherichia coli. Gene 64, 277-284.

Pezard, C., BerChe, P. \& Mock, M. (1991). Contribution of individual toxin components to virulence of Bacillus anthracis. Infection and Immunity 59, 3472-3477.

Quinn, C. P., Shone, C. C., Turnbull, P. C. B. \& Melling, J. (1988). Purification of anthrax-toxin components by high-performance anion exchange, gel filtration and hydrophobic-interaction chromatography. Journal of Biochemistry 252, 753-758.

RISTROPH, J. D. \& IVINs, B. E. (1983). Elaboration of a new, defined culture medium. Infection and Immunity 39, 483-486.

Sambrook, J., Maniatis, T. \& Fritsch, E. (1989). Molecular Cloning. A Laboratory Manual. Cold Spring Harbor, NY: Cold Spring Harbor Laboratory.

SMITH, H. \& Stoner, H. B. (1967). Anthrax toxin complex. Federation Proceedings 26, 1554-1557.

Stanley, J. L. \& Smith, H. (1961). Purification of factor I and recognition of the third factor of anthrax toxin. Journal of General Microbiology 26, 49-66.

STERNE, M. (1939). The immunization of laboratory animals against anthrax. Ondersterpoort Journal of Veterinary Science and Animal Industry 13, 313-317.

Towbin, H., Staehelin, T. \& GoRdon, J. (1979). Electrophoretic transfer of proteins from polyacrylamide gels to nitrocellulose sheets: procedure and some applications. Proceedings of the National Academy of Sciences of the United States of America 76, 4350-4354.

Trieu-Cuot, P., Carlier, C., Martin, P. \& Courvalin, P. (1987). Plasmid transfer by conjugation from Escherichia coli to $\mathrm{Gram}^{+}$ bacteria. FEMS Microbiology Letters 48, 289-294.

Trieu-Cuot, P., Carlier, C., Poyart-Salmeron, C. \& Courvalin, P. $(1990 a)$. A pair of mobilizable shuttle vectors conferring resistance to spectinomycin for molecular cloning in Escherichia coli and in Gram-positive bacteria. Nucleic Acids Research 18, 4296.

Trieu-Cuot, P., Poyart-Salmeron, C., Carlier, C. \& Courvalin, P. $(1990 \mathrm{~b})$. Nucleotide sequence of the erythromycin resistance gene of the conjugative transposon $\operatorname{Tn} 1545$. Nucleic Acids Research 18, 3660.

Uchida, I., Sekizaki, T., Hashimoto, R. \& Tirakado, N. (1985). Association of the encapsulation of Bacillus anthracis with a 60 megadalton plasmid. Journal of General Microbiology 131, 363-367.

VoDKIN, M. H. \& LEPPLA, S. H. (1983). Cloning of the protective antigen gene of Bacillus anthracis. Cell 34, 693-697.

Welkos, S. L. \& Friedlander, A. M. (1988a). Pathogenesis and genetic control of resistance to the Sterne strain of Bacillus anthracis. Microbial Pathogenesis 4, 53-69.

Welkos, S. L. \& Friedlander, A. M. (1988b). Comparative safety and efficacity against Bacillus anthracis of protective antigen and live-vaccines in mice. Microbial Pathogenesis 5, 127-139.

Welkos, S. L., Lowe, J. R., Eden-McCutchan, F., Vodkin, M, LEPPLA, S. H. \& SCHMIDT, J. J. (1988). Sequence and analysis of the DNA encoding protective antigen of Bacillus anthracis. Gene 69 , 287-300. 